\title{
Scientific Literacy: New Minds for a Changing World
}

\author{
PAUL DeHART HURD \\ Stanford University, Stanford, CA, USA
}

Received 9 April 1997; revised 25 August 1997; accepted 30 August 1997

\begin{abstract}
From the beginning of modern science in the 1600s, there has been an interest in how to link academic science with the lifeworld of the student. To facilitate this purpose requires a lived curriculum and a range of thinking skills related to the proper utilization of science/technology information. The extent to which students acquire these cognitive competencies determines whether or not they are scientifically literate. The supporting science curriculum must be culturally based and in harmony with the contemporary ethos and practice of science. Never before have schools faced such a rapidly changing landscape calling for a reinvention of school science curricula. This article identifies elements of a curriculum framework and cognitive strategies that seek to prepare students as productive citizens in today's world. () 1998 John Wiley \& Sons, Inc. Sci Ed 82:407-416, 1998.
\end{abstract}

\section{INTRODUCTION}

The cultural roots of scientific literacy go back in history to the introduction of modern science into Western civilization in the 1500s. In 1620, Francis Bacon noted that "The ideal of human service is the ultimate goal of scientific effort, to the end of equipping the intellect for a better and more perfect use of human reason." Bacon saw the subject matter selected to achieve this end should be that "which has the most for the welfare of man" (Dick, 1955, pp. 441, 487).

Thomas Jefferson, when vice-president of the United States in 1798, noted that little practical science was being taught in the schools at any grade level. He viewed the "sciences as keys to the treasures of nature . . . hands must be trained to use them wisely." Jefferson enlisted his friend DuPont de Nemours, a medical doctor and minister of agriculture in France, to survey the teaching of science in schools and to make recommendations for improvement. de Nemours reported that teachers said they had no textbooks that related science to practical affairs or that enhanced the 
progress of the country as a developing nation (de Nemours, 1923, pp. 55, 159). The U.S. Congress refused to grant the money to develop a science curriculum focused on social progress, contending this was a responsibility of the local community.

Herbert Spencer, a British philosopher, in 1859 examined the question of "What knowledge is most worth?" (Spencer, 1859, p. 5). He thought that whatever is chosen to teach should have "bearing on some part of life." He viewed the subject matter of school science courses at that time as a collection of "dead facts" that "fail to make clear any appreciable efforts which they can produce on human welfare" (p. 14). Spencer noted that nearly all aspects of industry, processes of living, and social development depended on science. He further noted that it was this knowledge being ignored in school science courses (p. 29).

Science courses make "the pupil a passive recipient of other's ideas and not in the least teaching [the student] to be an active inquirer or self-instructor" (p. 47). The result is that once examinations are over "the greatest part of what has been learned, being unorganized, soon drops out of recollecting ... . what remains is mostly inert - the art of applying not having been cultivated; and there is but little power either of accurate observation or independent thinking" (p. 47).

James Wilkinson, a member of the Royal College of Surgeons of London, delivered a special lecture in 1847 entitled "Science for All," in which he noted that the ends for which scientists create knowledge and those who seek the application of knowledge are not the same (Wilkinson, 1847). Scientists view knowledge as a private possession without regard for public service. Scientists want to be judged by their own peers and their own intentions rather than by the influence of their findings on the business of life. Wilkinson recognized that this approach excludes $99 \%$ of the population from the possible benefits of science discoveries. Consequently, most students faintly comprehend scientific facts and then forget them. This mode of teaching science fosters ignorance more than human understanding and the usefulness of science. Wilkinson stated "that the ends of man are the ends of science, and even of nature too, so far as nature can be presented to the human faculties" (p. 37).

In the 1930s the question of science education for all young people was again raised. In 1932, the executive board of the Progressive Education Association appointed a committee to explore "the needs of young people in the democratic society of America today." After 6 years of study and debate the science committee proposed goals for science teaching in terms of the impact of science on social progress, cultural patterns, and the life of the individual. The committee proposed a science curriculum based on the basic aspects of living: (1) personal living; (2) immediate personal-social relationships; (3) social-civic relationships; and (4) economic relationships (Report of the Committee on the Function of Science in General Education, 1937, p. 27).

After World War II it became evident that our nation was undergoing revolutionary changes in the nature and practice of science and its impact on the social, economic, and political aspects of the nation as well as on human welfare. Although 350 years have now elapsed since it was first proposed that a purpose of science education ought to be the contributions that science makes to public life and the common good, the appropriate curricula have yet to emerge. To bring this debate into focus led me to write the first article using the phrase scientific literacy as a goal of science education (Hurd, 1958).

A national committee of scientists and engineers was appointed by President Dwight Eisenhower in 1959 to consider the issue of how to use the knowledge of science and engineering "to advance social and cultural life" (President's Science Advisory Committee, 1959, p. 1). While not using the phrase "scientifically literate" the committee saw the need for a democratic citizenry that understands science for "intelligent democratic participation in many national decisions" (p. 21) and the place of science and technology in modern life. These comments represent a step toward building a civic dimension of scientific literacy.

During the 1950s and 1960s the National Science Foundation (NSF) course content programs viewed scientific literacy in terms of understanding the classical structure of disciplines and their 
mode of inquiry. The courses developed were discipline-bound and career-oriented rather than in a context focused on the utilization of scientific knowledge for the benefit of individuals, the common good, or social progress — "a science for all people" (Layton, 1973, chapter 8).

A valid interpretation of scientific literacy must be consistent with the prevaling image of science and the revolutionary changes taking place in our society. The following sections of this article consider these changes.

\section{THE CHANGING FACE OF SCIENCE}

Revolutionary changes in the nature, ethos, and practice of the sciences reveal a need to reexamine the traditional purposes of education in the sciences (Hurd, 1972, 1975). In 1970, the National Science Foundation (NSF) Advisory Committee for Science Education recommended that the traditional approach to science education in the sciences be rethought with more "emphasis on the understanding of science and technology by those who are not and do not expect to be professional scientists and technologists" (Report, 1970, p. iii). The implication is that notions of scientific literacy should be embedded in contexts that promote a socially responsible and competent citizen.

The traditional concept of a discipline (biology, chemistry, physics, earth science) as entities no longer have much meaning beyond that of cataloging university and school science courses. Disciplines have now become fractionated into an unknown number of research fields, without doubt thousands, each with its own language and research practices. There are now over 400 named fields of biology requiring more than 20,000 journals to report findings. The U.S. Library of Congress reports it receives over 80,000 scientific journals. The proper use of the word science today is in the plural-sciences.

From the beginning of modern science in the 1600s, instrumentation such as the telescope and microscope has had an important role in what scientists discover. Today, technology comes first in determining what is likely to be discovered. The Hubble telescope has added new dimensions to the study of astronomy that have as yet no theoretical base. The scanning tunneling microscope has done the same in biology. The latest microscope can focus on a single atom, thus revolutionizing biological research. A number of research projects today are on hold due to the lack of appropriate technology. Derek DeSolla Price, a philosopher of science, in his George Sarton Memorial Lecture at the 1983 national meeting of the American Association for the Advancement of Science, described contemporary science as "applied technology" (Price, 1983). Others have suggested such terms as "sci-tech" and "technoscience" to characterize today's science. My preference for the time being is science/technology.

Fields of scientific/technological research today are being increasingly hybridized; for example, biogeochemistry, biophysics, astrophysics, biomedicine, neurobiology, laser chemistry, and human ecology. At the rate of hybridization it is anticipated that sometime in the early part of the $21 \mathrm{st}$ century there may be but one science (Branscomb, 1981). At the beginning of this century, research in the sciences was concentrated in the physical sciences. Now, at the close of this century, the biological sciences are the center of attention.

Science today is changing in other ways. Less attention is being devoted to the establishment of new theories and laws, a procedure formerly recognized as basic research. Today more attention is focused on the functional aspects of science/technology as it relates to human welfare, economic development, social progress, and the quality of life. This trend is identified as strategic research.

Science is also becoming more holistic in nature, blending the natural and social sciences. This transdisciplinary approach provides for a broader form of research for dealing with science/social problems. Examples are: wellness, new energy sources, environment problems, research on learning and memory, human development, improvement of plants and animals through biotechnology, and the human ecosystem. These and related efforts influence how we live, learn, and work. Having begun in October 1997, scientists seeking funds from the National Science Foundation to support 
their research must now indicate how their expected findings are likely to benefit the economy, social progress, and science education (Mervis, 1997).

Another change in the practice of contemporary science is the move from single disciplinary based studies to cross-disciplinary or transdisciplinary approaches involving teams of researchers (Spiegel-Rösing and Price, 1977). Increasingly, cross-disciplinary research is a joint product of scientists and social scientists. For example, in the research on AIDS scientists seek the cause and cure while social scientists are primarily concerned with the prevention and control of the AIDS pandemic.

Today, $95 \%$ of research reports are multiauthored; at the beginning of this century the number was 5\%. The 12 most cited papers published worldwide in 1991 had an average of 5.3 authors per article, and no paper had fewer than four authors (Institute for Scientific Information, 1993). This approach to a problem extends the meaning of science beyond the laboratory walls by adding a social dimension (Berkner, 1964; Ziman, 1968). As a result science/technology becomes a cultural force (Woolf, 1964).

A concept of scientific literacy must recognize the range of changing forces in our society. Examples include such changes as the emergence of an information age, the birth of a global economy, and new ways of communication (the cyberworld). These changes provide a basic framework for constructing a meaning for scientific literacy that includes the ability of optimal use of science/technology knowledge (Boulding and Senish, 1983). Efforts to effect a supporting curriculum have been in progress for over 350 years (Longino, 1990; Hurd, 1970, pp. 13-20; Husén and Keeves, 1991). The idea that the emphasis on knowing should be on the utilization of knowledge was recognized by Confucius some 2500 years ago when he wrote that "the essence of knowledge is, once obtained, is to use it" (RANN 2, 1976, p. 23).

Increasingly, research in science/technology today is done by teams rather than by a single researcher. Teams may consist of a mixture of scientists from related fields, or of natural scientists and social scientists. A computer expert is an essential member of a research team. Computers, sometimes with the help of intelligent robots, keep track of observations and measurements, reveal possible relationships within a collection of data, and otherwise assist in research efforts. The team approach in the contemporary practice of science/technology is viewed as a cognitive system with a greater potential for increasing the fertility of hypothesis and discovery than an individual working alone.

Over the past half-century the center for research in science/technology has moved from universities to industry. Today $60 \%$ of all scientists are employed in industry, $35 \%$ in universities, and $5 \%$ are self-employed. Industries are interested in the commercial application of science findings. This raises the question about who owns scientific/technology knowledge produced in industry. University scientists have typically valued science knowledge for its own sake and made it available to anyone who can use it.

Science/technology research is increasingly targeted on social and economic affairs (Carnegie Commission, 1991; New York Academy of Sciences, 1995), a transition of science from the laboratory to the "real world" and "real life." Efforts to transform science education into that same context have been intellectually stalled, for the most part by a failure to recognize the socialization of today's science/technology. Scientific literacy is seen as a civic competency required for rational thinking about science in relation to personal, social, political, economic problems, and issues that one is likely to meet throughout life. The science-technology-society (STS) movement provides a framework for inventing school science curricula relevant to the life of every student. At the college-university level there has been considerable effort to rethink the nature of a general education in the sciences consistent with the culture and practice of contemporary science and social issues (Curriculum Newsletter of Lehigh University, 1997; EVIST Research Directory, 1978). 


\section{MODERNIZING SCHOOL SCIENCE}

For centuries, the approach to science curricula improvement has been simply to update the subject matter of traditional disciplines. A failure to recognize changes in either the practice of science or shifts in our culture continues. Albert Einstein once noted that the significant problems we face cannot be solved at the same level of thinking as when we created them. Although the nature of science/technology research today is focused mostly on its functional uses in terms of applications to human welfare and the common good, school science curricula in the same context are practically nonexistent. The proposed national standards, benchmarks, and themes of science in their current state are in the traditional mode of curriculum development, although personalsocial dimensions are recognized.

The revolutionary changes in the practice and culture of today's science/technology also call for major changes in how science curricula are developed and how the full meaning of scientific literacy should be defined. At the 1997 annual meeting of the American Association for the Advancement of Science (AAAS) the board of directors voted unanimously to ask the scientific community to rethink the direction of research toward addressing "the most serious problems facing humanity." These include problems such as health and disease, the stabilization of the natural environment, new modes of communication, the development of new energy sources, aging patterns of the human organism, and a wider use of biotechnology for the improvement of food resources. To meet these challenges requires a new vision of science education and a new vision of scientific literacy. The debate on an appropriate meaning for scientific literacy is now in progress (American Association for the Advancement of Science, 1993; Bauer, 1992; Bybee, 1997; Rutherford \& Ahlgren, 1989; Shamos, 1995).

International perspectives on scientific literacy are harbored in the debate on science-technology-social relationships (Solomon \& Aikenhead, 1994); for instance, in the journals Science, Technology \& Human Values, Science and Education, and Social Studies of Science. The Republic of China views "STS as learner-centered and issue-oriented linked to the real life outside the classroom" (Proceedings of the National Science Council, Republic of China, 1997).

The move toward a national science curriculum in the United States begins with the identification of human personal-social experiences at various levels of schooling and the use of science/technology knowledge in resolving associated problems, such as understanding one's self, and ways in which the natural and social environments influence living. For over a century science curriculum reformers have justified their efforts in terms of "meeting the needs of students"; these needs have yet to be described in teachable terms.

Education in the sciences takes on new dimensions with the changing image of science/technology, a rapidly changing culture, and a knowledge-intensive era. Human beings are the only living organism whose adaptive capacity is primarily a learned one. The level of one's ability to use advances in science/technology for improving various aspects of one's life is now viewed as building "human capital." In this context, scientific literacy represents cognitive capacities for utilizing science/technology information in human affairs and for social and economic progress.

Throughout the first 25 years of today's science education reform movement it has been stated repeatedly that science curricula need to be reinvented to harmonize with changes in the practice of science/technology, an information age, and the quality of life. What is sought is a lived curriculum in which the major instructional standards and intellectual skills are those to enable individuals to cope with changes in science/technology, society, and the dimensions of human welfare. Most science curricula found in schools today are descriptive, focused on the laws, theories, and concepts of presumably discrete disciplines. In contrast, the lived curriculum is where students have a feeling that they are involved in their own development and recognize that they can use what they learn. This venture in science curriculum development recognizes the socialization of science and its relevance to how science impacts our culture, our lives, and the course of our democracy. 
The development of a lived curriculum in science/technology will require cooperative endeavors with specialists in the social sciences and the humanities, as well as in such fields as ethics, the judiciary, and political science. The National Institute of Child Health and Human Development (NICHD) has adopted a unifying research theme centered on "human development in all its aspects," including "learning and behavioral development" throughout life (Mack, 1997, pp. 11-12). The central question is: What really counts in the sciences for living in this new and changing age we are experiencing? The move shifts science instruction toward modes of social inquiry beyond the traditional discipline-bound notions of scientific inquiry. During the 1980s and 1990s concerted efforts have been and are being made to identify social and higher order thinking skills associated with science/technology literacy that may serve as a framework for developing a lived curriculum. The curriculum sought is one that prepares students to cope with the changes influencing human welfare.

A sampling of the personal, social, and cognitive concepts that students need to acquire include:

- Health (biological, behavioral, social, environmental).

- Wellness (fitness and safety, optimizing biological systems).

- Knowledge of oneself (human nature, human identity).

- Environment (ecological and environmental protection).

- Communication systems (sources, processing, and utilization of information).

- Science (technology, social, and cultural interactions).

- Growth and development (from birth through old age).

- Factors in learning how to learn (self-directed learning, building human capital, knowing processes).

- Human social interactions and collaboration in resolving civic problems.

- Human diversity (individual, cultural, and value systems).

- Quality of life (criteria, social, biological, aesthetic, physical elements).

- Real-life problem solving (decisionmaking, practical thinking, making judgments, taking action).

- Changed images of science (historical, current, and future perspectives).

- Unsolved problems in science/technology ("the endless frontier").

- Contemporary science and public policy.

- Food and agriculture (biotechnology, genetic engineering).

- Life skills (personal and social adjustment).

- Public health (illegal drugs, control of pandemics, war on cancer, sexually transmitted diseases).

- Dynamics of human population growth (population explosion).

- Diversity in ecosystems (species extinction).

- Energy (resources and controls).

- Ethical, value, moral, and judicial issues in science/technology.

- Participation in community-science-related activities (recycling, urban transportation, sanitation).

- Genetic continuity in humans, plants, and animals (biotechnology).

- Exploration of the biological and physical worlds (awareness, experiencing nature, earth system and global changes).

- Strategic research in science/technology in relation to human and social affairs and the quality of life.

- Initiation of action programs related to human and social welfare. 


\section{FRAMING THE MEANING OF SCIENTIFIC LITERACY}

Behaviors associated with the production and utilization of science knowledge in human affairs represent the civic basis of scientific literacy. This perception is a blend of the revolutionary changes in the sciences with dimensions of our democracy, social progress, and the adaptive needs of human beings.

The elements of a civic concept of scientific literacy represent a consciousness of behaviors that serve as guidelines for interpreting the functions of science/technology in human affairs and the management of one's life. These behaviors also serve as guidelines for reinventing science curricula in grades $\mathrm{K}-12$, which has been called for in the education reform movement. The following attributes are among others that enable students to adapt to the changing world of science and technology and its impact on personal, social, and economic affairs. Thus, a scientifically literate person is one who:

- Distinguishes experts from the uninformed.

- Distinguishes theory from dogma, and data from myth and folklore. Recognizes that almost every fact of one's life has been influenced in one way or another by science/technology.

- Knows that science in social contexts often has dimensions in political, judicial, ethical, and sometimes moral interpretations.

- Senses the ways in which scientific research is done and how the findings are validated.

- Uses science knowledge where appropriate in making life and social decisions, forming judgments, resolving problems, and taking action.

- Distinguishes science from pseudo-science such as astrology, quackery, the occult, and superstition.

- Recognizes the cumulative nature of science as an "endless frontier."

- Recognizes scientific researchers as producers of knowledge and citizens as users of science knowledge.

- Recognizes gaps, risks, limits, and probabilities in making decisions involving a knowledge of science or technology.

- Knows how to analyze and process information to generate knowledge that extends beyond facts.

- Recognizes that science concepts, laws, and theories are not rigid but essentially have an organic quality; they grow and develop; what is taught today may not have the same meaning tomorrow.

- Knows that science problems in personal and social contexts may have more than one "right" answer, especially problems that involve ethical, judicial, and political actions.

- Recognizes when a cause and effect relationship cannot be drawn. Understands the importance of research for its own sake as a product of a scientist's curiosity.

- Recognizes that our global economy is largely influenced by advancements in science and technology.

- Recognizes when cultural, ethical, and moral issues are involved in resolving science-social problems.

- Recognizes when one does not have enough data to make a rational decision or form a reliable judgment.

- Distinguishes evidence from propaganda, fact from fiction, sense from nonsense, and knowledge from opinion.

- Views science-social and personal-civic problems as requiring a synthesis of knowledge from different fields including natural and social sciences. 
- Recognizes there is much not known in a science field and that the most significant discovery may be announced tomorrow.

- Recognizes that scientific literacy is a process of acquiring, analyzing, synthesizing, coding, evaluating, and utilizing achievements in science and technology in human and social contexts.

- Recognizes the symbiotic relationships between science and technology and between science, technology, and human affairs.

- Recognizes the everyday reality of ways in which science and technology serve human adaptive capacities, and enriches one's capital.

- Recognizes that science-social problems are generally resolved by collaborative rather than individual action.

- Recognizes that the immediate solution of a science-social problem may create a related problem later.

- Recognizes that short- and long-term solutions to a problem may not have the same answer.

These science literacy characteristics are not taught directly but are embedded in a lived curriculum where students are engaged in resolving problems, making investigations, or developing projects. Supporting laboratory and field experiences are viewed as exercises in citizenship. As teachers we need to recognize constantly that public understanding of science is conceptually different from the traditional forms embedded in the structure of science disciplines.

\section{SUMMARY}

This article portrays the 350-year history of efforts to close the gap between academic science and science for the citizen. Today this deficiency has become an international dilemma represented by the science-technology-society movement. The situation is more complicated than in the past because of the changing image in the practice of science, revolutionary changes in societies, and the emmergence of an information age. These forces have outmoded current curricula in science and their goals.

Science education for all students is seen as curricula that can be lived and that students can relate to. In addition, cognitive insights needed by students to select, organize, and utilize science knowledge for a productive life are listed. Students who possess these higher order thinking skills and cognitive strategies are regarded as scientifically literate.

The philosophical stimulus for writing this article came from Aristotle (384-322 B.C.). After surveying the schools of Rome he wrote:

There is no general agreement about what a young person should learn, either in relation to more virtue or to success in life. The existing practice is perplexing; no one knows on what we should proceed - should the useful in life, or should virtue, or should the higher knowledge, be the aim of our training; all three opinions have been entertained. Again, about the means there is no agreement; for different persons, starting with different ideas about the nature of virtue, naturally disagree about the practice of it. There can be no doubt that children should be taught those useful things which are really necessary . . . . (Jewett \& Hutcher, 1964, p. 268)

For modern times it is science/technology literacy, a lived curriculum, and an understanding of the current practice of research in science/technology that are needed to make science useful in our lives. 


\section{REFERENCES}

American Association for the Advancement of Science. (1993). Benchmarks for science literacy: Project 2061. New York: Oxford University Press.

Bauer, H. H. (1992). Scientific literacy and the myth of the scientific method. Chicago: University of Illinois Press.

Berkner, L. V. (1964). The scientific age: The impact of science on society. New Haven, CT: Yale University Press.

Boulding, K. E., \& Senesh, L. (1983). The optimal utilization of knowledge: Making knowledge serve human betterment. Boulder, CO: Westview Press.

Branscomb, L. (1981). Only one science: Twelfth annual report of the National Science Board. Washington, DC: U.S. Superintendent of Documents.

Bybee, R. W. (1997). Achieving scientific literacy: From purposes to practices. Portsmouth, NH: Heinemann. Carnegie Commission Report. (1991). In the national interest: The federal government in the reform of $K-$ 12 math and science education. New York: Author.

Curriculum Newsletter of Lehigh University. (1997, ongoing). Science, Technology and Society. Bethlehem, PA: Lehigh University STS Program.

de Nemours, D. (1923). National education in the United States. Newark, DE: University of Delaware Press. Dick, H. (Ed.). (1955). Selected writings of Francis Bacon. New York: Random House.

EVIST Resource Directory. (1978). Programs in the field of ethics and values in science and technology. Washington, DC: American Association for the Advancement of Science.

Hurd, P. D. (1958). Science literacy: Its meaning for American schools. Educational Leadership, 16, $13-16$.

Hurd, P. D. (1970). Scientific enlightenment for an age of science. The Science Teacher, 37, 13-16.

Hurd, P. D. (1972). Emerging perspectives in science teaching for the 1970s. School Science and Mathematics, 72, 765-772.

Hurd, P. D. (1975). Science, technology, and society: New goals for interdisciplinary science teaching. The Science Teacher, 42.

Husén, T., \& Keeves, J. P. (1991). Issues in science education: Science competence in a social and ecological context. New York: Pergamon Press.

Institute for Scientific Information. (1993). Scientific papers: The producers of 1991. Science, 5092, 180.

Jewett, B., \& Hutcher, S. H. (Trans.). (1964). Aristotle: Politics and poetics (book eight). New York: The Heritage Press.

Layton, D. (1973). Science for the people. New York: Science History Publications.

Longino, H. E. (1990). Science as social knowledge: Values and objectivity in scientific inquiry. Princeton, NJ: Princeton University Press.

Mack, A. (1997). NICHD's broad mission spans disciplines, stages of life. The Scientist, 11.

Mervis, J. (1997). NSF adopts new guidelines. Science, 276, 26.

New York Academy of Sciences. (1995). Science, technology, and the 104th Congress: Perspectives on new choices. New York: Author.

President's Science Advisory Committee. (1959). Education for the age of science. Washington, DC: The White House.

Price, D. D. (1983). Sealing wax and string a philosophy of the experimentor's craft and in the genesis of high technology. Tape recording of Association for the Advancement of Science 83-3.

Proceedings of the National Science Council, Republic of China. (1997). Mathematics, Science, and Technology Education, 7, 69.

RANN 2. (1976). Realizing knowledge as a resource. Vol. I. Washington, DC: National Science Foundation. Report of the Advisory Committee for Science Education. (1970). The task ahead for the National Science Foundation (NSF Publication No. 71-13). Washington, DC: National Science Foundation.

Report of the Committee on the Function of Science in General Education. (1937). Science in general education. New York: D. Appleton-Century.

Rutherford, F. J., \& Ahlgren, A. (1989). Science for all Americans. New York: Oxford University Press.

Shamos, M. H. (1995). The myth of scientific literacy. New Brunswick, NJ: Rutgers University Press.

Solomon, J., \& Aikenhead, G. S. (Eds.). (1994). STS education: International perspectives on reform. New York: Teachers College Press. 
Spencer, H. (1859). Education: Intellectual, moral and physical. New York: J. B. Alden.

Spiegel-Rösing, I, \& Price, D. D. (Eds.). (1977). Science, technology, and society: A cross-disciplinary perspective. Beverly Hills, CA: Sage Publications.

Wilkinson, J. J. G. (1847). Science for all. London: William Newberry.

Woolf, H. (Ed.). (1964). Science as a cultural force. Baltimore, MD: Johns Hopkins University Press.

Ziman, J. M. (1968). Public knowledge, the social dimension of science. Cambridge, UK: University Printing House. 